Max-Planck-Institut für demografische Forschung

Max Planck Institute for Demographic Research

Konrad-Zuse-Strasse 1 - D-18057 Rostock - GERMANY

Tel +49 (0) 3812081 - 0; Fax +49 (0) 3812081 - 202;

http://www.demogr.mpg.de

MPIDR WORKING PAPER WP 2014-009

OCTOBER 2014

\title{
Regional mortality disparities in Germany: Long-term dynamics and possible determinants
}

\author{
Eva Kibele \\ Sebastian Klüsener (kluesener@demogr.mpg.de) \\ Rembrandt Scholz (scholz@demogr.mpg.de)
}

This working paper has been approved for release by: Vladimir Shkolnikov (shkolnikov@demogr.mpg.de), Head of the Laboratory of Demographic Data.

(C) Copyright is held by the authors.

Working papers of the Max Planck Institute for Demographic Research receive only limited review. Views or opinions expressed in working papers are attributable to the authors and do not necessarily reflect those of the Institute. 


\section{Regional mortality disparities in Germany Long-term dynamics and possible determinants}

Eva Kibele ${ }^{1,2}$, Sebastian Klüsener ${ }^{3}$, Rembrandt Scholz ${ }^{3}$ 1 Population Research Centre, Faculty of Spatial Sciences, University of Groningen, the Netherlands 2 Healthy Ageing: Population and Society (HAPS), University of Groningen, the Netherlands

3 Max Planck Institute for Demographic Research, Germany 


\begin{abstract}
While regional mortality inequalities in Germany tend to be relatively stable in the short run, over the course of the past century marked changes have occurred in the country's regional mortality patterns. These changes include not only the re-emergence of stark differences between eastern and western Germany after 1970, which have almost disappeared again in the decades after Germany's unification in 1990; but also substantial changes in the patterns in northern and southern Germany. By the end of the $19^{\text {th }}$ century, the northern regions in Germany had the highest life expectancy levels, while the southern regions had the lowest. Today, this mortality pattern is reversed. In this paper, we study these long-term trends in spatial mortality disparities in Germany since 1900, and link them with theoretical considerations and existing research on the possible determinants of these pattern. Our findings support the view that the factors which contributed to shape spatial mortality variation have changed substantially over time, and suggest that the link between regional socioeconomic conditions and mortality outcomes strengthened over the last 100 years.
\end{abstract}

Keywords: regional mortality; mortality trends; socioeconomic conditions; (eastern and western) Germany 


\section{Background}

Since 1900, German society, like many other societies across the globe, has undergone a number of fundamental developmental processes which have led to substantial improvements in the survival chances of its individual members. In the literature this rapid rise in life expectancy is often referred to as the longevity revolution (Robine et al. 2009). At the beginning of the $20^{\text {th }}$ century, large parts of German society could still be characterised as agrarian. However, rapid industrialisation in the second half of the $19^{\text {th }}$ century had already spurred urban growth. Particularly in big cities, governments struggled to alleviate the poor hygienic conditions which contributed to an urban penalty in survival chances (Woods 2003). Infectious diseases were the primary causes of death, and infant mortality was high. Today, on the other hand, the death of an infant has become a rare event, and cardiovascular diseases and cancer have emerged as the leading causes of death.

These shifts have also contributed to a growing gap in the survival chances of people based on their social status (Bengtsson and van Poppel 2011). In spatiotemporal contexts with unfavourable hygienic conditions and a high prevalence of infectious diseases, individuals of higher socioeconomic status face difficulties in translating their better access to resources into improvements in survival chances. But socioeconomic status may be more relevant in contexts in which infectious diseases are less likely to become fatal, and in which the main causes of death are diseases that can be treated with resource-intensive medical interventions. Thus, we might expect the survival chances of individuals in highly developed societies to be much less affected by uncertainties and randomness, and to be much more dependent on their access to assets (e.g., human and financial capital).

Germany is well suited for an investigation of regional mortality differences, as in the early $20^{\text {th }}$ century it appears to have been the European country with the highest degree of sub-national mortality variation (Klüsener et al. 2014). Germany had long been divided into dozens of independent states which differed in terms of their economic structures and their prevailing religious and social norms. Even today, Germany has a highly federalised structure, which is, e.g., apparent in the organisation of the health care and educational system. Its location in central Europe, at the crossroads between western and eastern Europe, makes Germany a particularly interesting case to study. Europe has long been characterised by substantial east-west differences in mortality conditions (Vallin and Meslé 2001), which are reflected to some extent in Germany's regional mortality patterns.

Many studies on variation in longevity have focused on the national level, and have often provided cross-country comparisons (Leon 2011; Meslé and Vallin 2002; Nolte et al. 2000a; Omran 1998; Vallin and Meslé 2001). However, national averages might hide substantial variation across sub-national regions of a country (Bonneux et al. 2010; Shaw et al. 2000). In some cases, these national means might even paint a misleading picture (Johansson and Kasakoff 2000). For example, if a country exhibits high levels of infant mortality in the north and low levels in the south, the mean national levels will not be representative of either of the two parts of the country. Studies with sub-national data allow us to look into these regional discrepancies. In addition, investigating how regional variation patterns have changed over time is likely to improve our understanding of the potential determinants which facilitated or limited the longevity revolution at different periods of time. These factors might include spatial variation in the compositional characteristics of populations or of contextual circumstances, such as socioeconomic and ecological conditions.

In recent decades, a large number of studies have examined regional mortality differences in Germany. However, most of these studies have focused on disparities between East and West Germany after the division of the country in 1945 , or on regional mortality differences at some point in time after 1990 (Cromm and Scholz 2002; Kibele 2012; Luy 2004; Vogt 2013). Our study broadens this focus not only by taking a longer-term perspective over a whole century, but also by providing a higher degree of spatial detail. The use of this approach allows us to explore variation within eastern and western Germany. To our knowledge, this is the first study which has taken such a long-term 
view on regional mortality disparities for Germany. Our paper has two main aims. The first is to provide an overview of the theoretical considerations regarding the factors which have contributed to spatial variation in survival conditions at different stages of the longevity revolution. The second is to compare these theoretical models with descriptive evidence on the development of regional mortality differences within Germany.

\section{Theoretical considerations}

Theoretical and conceptual models which seek to explain regional mortality differences are scarce in the demographic literature; and there are even fewer theoretical models which attempt to explain changes in regional mortality differences over time. Most of the scholars who have engaged in the discourse on explanatory models are in the fields of health sciences (Kawachi and Berkman 2003; Lalonde 1974), geography (Gatrell 2002; Howe 1986), or both (Shaw et al. 2002). Our theoretical considerations benefit considerably from Lalonde's health field concept (1974), which focuses on mortality disparities; and from Omran's epidemiologic transition theory (1998), which seeks to explain mortality decline over time.

\subsection{Explaining regional mortality variation by population composition and regional context}

In the 1970s, the Canadian Department of Health and Welfare developed the health field concept, which acknowledged the important role that non-medical factors play in health, and provided a classification of these factors (Howe 1986; Lalonde 1974). The concept was originally developed to depict and explain health disparities, and to support policy interventions (cf. Kickbusch 2003). The health field concept envisaged that the health field can be broken down into four elements: human biology, the physical and social environment, individuals' lifestyle, and the health care system (Lalonde 1974). In line with Lalonde, we also assume that regional mortality disparities originate from both macro-level conditions and regional variation in individual-level characteristics and behaviour. Individual-level determinants of mortality can influence regional mortality variation if the compositional characteristics of populations in terms of individual attributes vary across regions. For example, there may be variation in the share of academics or in the share of smokers. Regional differences might be enforced through social interactions in which spatial distance can moderate the frequency and intensity of interactions between individuals; e.g., a higher prevalence of smokers in an area might increase the likelihood that other people who live in the area will start to consume tobacco products. Other macro-level influences, which are also referred to contextual effects, include spatial variation in socioeconomic, political, and ecological conditions (Diez Roux 2002; Shaw et al. 2002; Valkonen 2001).

Over the past two decades, one of the key issues raised in the scientific debate on spatial variation in health and survival outcomes has been how best to disentangle compositional and contextual effects. Scholars who have attempted to address this question have often used multilevel models (Diez Roux 2002; Kawachi \& Berkman 2003; Tunstall et al. 2004). These models allow to distinguish influences at different levels of aggregation (e.g. individuals nested in regions and/or countries). Empirical findings based on multilevel models suggest that while individual-level characteristics determine to a large extent the lifespans of individuals living in modern societies, there are also independent contextual effects on mortality. Mortality is usually higher for individuals who live in areas with less favourable socioeconomic conditions (Meijer et al. 2012). This seems particularly to be true for people of lower socioeconomic status (Kibele 2014; Riva et al. 2007; Tunstall et al. 2004).

\subsubsection{Population composition: Individual-level mortality determinants}

Age and gender are the strongest mortality predictors. However, mortality measures usually standardise for differences in age structure, and are presented sex-specifically. This is also the case in 
our study. Age is an important factor, not only because of the biological accumulation of health risks and diseases over an individual's life course, but also because social factors, such as social inclusion and access to assets, can vary systematically across the lifespan. Moreover, gender differences in mortality risks are related to both biological and social factors (Luy 2002). Genetics play a major role in determining individuals' mortality risks (Christensen and Vaupel 1996). Nevertheless, genetic shifts appear to have contributed very little to the massive improvements in survival chances among European societies during the longevity revolution of the last two centuries (Burger et al. 2012). Thus, while studies have found that similarities in genetic characteristics are decreasing by spatial distance across Europe (Lao et al. 2008; see also Barbujani and Sokal 1990), the role of genetics in determining regional variation in the longevity revolution is probably small.

The elements of an individual's lifestyle which are generally referred to as health behaviours-such as nutrition, physical activity, and smoking and drinking habits-are strongly and directly related to mortality risks. These health behaviours differ regionally. Variation was observed during the time when Germany was divided, as East Germans had more limited access to healthy foods (Diehl 2008; Nolte et al. 2000b). Lifestyle and health behaviours are strongly correlated with socioeconomic status, which is another important survival determinant at the individual level. The socioeconomic position of an individual within a society not only influences the person's lifestyle, but also has an independent effect on his or her mortality (Adler and Ostrove 1999). Thus, a person's socioeconomic position is usually strongly linked to his or her access to financial assets, such as income and savings; human capital, including education and health status; and infrastructure capital, such as good housing. Spatial variation in occupational characteristics can also contribute to disparities in mortality outcomes. For example, mining regions have a high share of miners, who have elevated mortality risks (Tunstall et al. 2004). Access to social capital (Bourdieu and Wacquant 1992), which may, for example, affect access to informal care and social inclusion at older ages, can also vary across regions.

Selective migration can substantially influence the regional population composition, as regions and cities which offer more job opportunities are particularly attractive in-migration destinations for people both within and outside of the country. Migration is often health-selective: i.e., migrants tend to be healthier than stayers (Boyle 2004), although this effect may be reversed when migrants reach older ages (Kibele and Janssen 2013).

\subsubsection{Regional context: Macro-level mortality determinants}

Our considerations on the macro-level mortality determinants existing in the social and spatial contexts in which individuals are embedded in are based on a relational conceptualisation of space (see Cummins et al. 2007 for a detailed discussion). In this relational view, an individual is seen as a person whose spatial location attributes are not time-constant, and are subject to systematic and unsystematic changes at various temporal scales (e.g., daily routines, life course-related migration strategies). The frequency and the quality of the person's contacts with other individuals, and his or her access to assets, societal institutions, or elements of the infrastructure (e.g., the health care system) can be, but are not necessarily, moderated by the absolute geographic distances between the individual and certain objects. The importance of absolute geographic distances has also been substantially reduced over our study period as a result of innovations in transport and communication technologies (Harvey 1990). Some macro-level determinants may be related to discrete spatial areas (e.g., specific regional policies), while the relevance of others might vary in a fluid manner across space, with no discrete boundaries. Some factors can vary substantially across small areas (e.g., neighbourhoods), while others might exhibit more variation at lower levels of spatial detail (e.g., bigger regions within a country). There may also be associations between individual attributes and contextual conditions; e.g., the health effects of living in a deprived area might be moderated by socioeconomic status. 
The degree to which the administrative territorial divisions we refer to in studying variation in life expectancies are relevant for understanding the macro-level determinants also depends on the social relevance of these divisions. While Germany was divided, the border between eastern and western Germany was of considerable relevance, as it divided the country into two areas with little social interaction and with very different political and economic systems. Also the division in 1910 was mainly based on administrative boundaries, which constituted state borders between the different independent German states for a long time. These states had displayed substantial variation in their social, economic, and political dimensions. Even today, Germany has a decentralised political structure in which the federal states (Bundes/änder) still play a role in organising the health care infrastructure and in formulating regional education and economic development policies. There is also substantial variation in socioeconomic conditions across the German federal states.

Contextual factors include variation in socioeconomic and ecological conditions and in (regional) policies; and spatial variation in access to infrastructure, such as housing and health and emergency care (see also Diez Roux 2002). Particularly for historical patterns, variation in religious norms and in the extent to which mothers breastfed their infants also affected mortality outcomes (van Poppel 1992). In regions with unfavourable social and economic conditions, a culture of anomie might emerge (Shaw et al. 2002). This culture may foster the spread of unhealthy lifestyles. Access to health infrastructure might exhibit a centre-periphery gradient, as people living in big cities may benefit from having better access than people living in peripheral areas to specialised hospitals and short rescue times in case of emergencies, such as heart attacks (Koch et al. 2008).

\subsection{Explaining mortality decline and regional differences in mortality decline}

Given the large number of determinants of regional mortality and the complexity of these influences, it is not surprising that explaining changes in regional mortality differences is a complicated task (Valkonen 2001). Changes in regional mortality should be attributable to changes in different regions in the risk factors at both the individual and the contextual levels. The importance of various mortality determinants may fluctuate over time, and changes in risk factors are translated into disease patterns, often with a temporal delay (Kuh et al. 2004; Valkonen 2001).

Omran's epidemiologic transition theory, which has been developed since the 1970s, serves as a guideline for explaining changes in (regional) mortality patterns over time (Omran 1998). Over our study period of 1910 until today, Germany transitioned from being at the end of the second stage of receding pandemics (epidemic peaks decrease in frequency, still limited access to health care and sanitation; improvements in housing conditions); to the third stage of degenerative, stress, and manmade diseases (manifestation of cardiovascular and other degenerative diseases; widespread access to preventive and curative health care); and finally to the fourth stage of declining cardiovascular mortality, aging, lifestyle modification, and emerging and resurgent diseases (starting with cardiovascular revolution in the 1970s; sustained chronicity and ageing; deliberate modifications in health-related lifestyle and health care interventions on risk factors of chronic diseases) (Omran 1998).

At the beginning of the $20^{\text {th }}$ century, infectious diseases were the most important cause of mortality. But as the prevalence of these diseases sharply declined, there were significant reductions in infant, child, and maternal mortality rates (Omran 1998; Schofield et al. 1991). Public health measures related to hygiene and nutrition increased living standards. In particular, the installation of water mains and sewage disposal systems led to a decline in mortality (Omran 1998; Vallin and Meslé 2001). In Germany, sewage and drinking water purification systems were first introduced in cities at the start of the industrial revolution, from 1850 to 1880 . There is, however, little empirical evidence of a direct link between the reduction in infant mortality and these public health measures (van Poppel and van der Heijden 1997; Wolleswinkel-van den Bosch 1998). The regions that industrialised early did not necessarily provide healthier living environments. Instead, the working conditions at the 
onset of industrialisation led to increases in mortality due to hard physical labour, exposure to toxic substances, and accidents (Wolleswinkel-van den Bosch 1998).

Most medical innovations-such as antibiotics, surgical innovations, and perinatal care-became effective after 1930, when infectious disease mortality has already dropped significantly due to social advances and hygiene (Omran 1998; Wolleswinkel-van den Bosch 1998). A stronger link between medical advancements and mortality improvements seems, however, to exist for the cardiovascular revolution that started in the 1970s (Vallin and Meslé 2001). Medical care improvements contributed substantially improving survival chances at older ages. Overall, the longevity revolution has been fostered by socioeconomic, political, and cultural factors, including lifestyle choices related to health, nutrition, and living standards, as well as by medical and public health advances. The effects of each of these factors on mortality also changed over time (Omran 1998; Vallin and Meslé 2001).

\section{Data and methods}

\subsection{Data and analytical strategy}

In the empirical part of this paper, the regional mortality patterns and trends are described and discussed in relation to potential explanatory factors found in the literature. We first present trends in life expectancy between 1910-11 and 2009-11 and the decomposition of life expectancy changes over time for eastern and western Germany in order to show which age groups in particular benefited from improvements at different times (Statistisches Bundesamt 2012a; 2012b).

We then focus on changes in regional mortality variation over the last 100 years. One challenge we faced in conducting our analysis is that Germany has undergone several changes in both its external and its internal administrative boundaries over the last 100 years. Particularly drastic were the changes in eastern Germany, as the regional divisions which existed in the GDR era differed substantially from those which existed prior to 1945. Meanwhile, the administrative divisions enacted in eastern Germany after 1990 again reflected long-standing regional divisions, at least to some degree. In western Germany, by contrast, there has been a relatively high degree of continuity in administrative boundaries over time, at least at the level of the states. As our paper is a descriptive account of how mortality differences developed over time, these changes are not of immediate concern for our analysis. Nevertheless, we need to be aware that changes in the number of regions different parts of Germany contribute to the overall number of regions can affect the colour categorisation schemes in the maps.

We decided to present data on regional mortality variation for the following periods: 1910, 1970, and 1995-2011. These time periods were chosen based on theoretical and data availability considerations. The year 1910 marks the end of a rather peaceful period which the German Empire experienced after it was unified in 1871. In these decades, the country witnessed rapid economic development and the emergence of a national welfare system. For the cross-section of 1910 we obtained age-group specific mortality rates for the states and territories of the German Empire for the period 1908-1913. This data allows to subdivide the biggest German state Prussia in its provinces and the second-biggest state Bavaria into the parts east and west of the Rhine (Statistisches Reichsamt 1918; $\mathrm{N}=40$ ). Based on this data, we calculated life expectancy measures.

We decided not to collect data for a cross-section in the rather turbulent time period between 1914 and 1961, during which Germany experienced two wars and substantial migration streams from east to west. Instead, we chose the time period around 1970 as the second cross-section. This time period marks the beginning of the emergence of distinct differences between East and West Germany in terms of mortality developments (Luy 2004). This was also approximately the time when the southern part of West Germany could establish itself as the economically most advanced area in West Germany. The data for the West German regions (Bundesländer; N=11) for the period 1970-72 
were obtained from regional life tables calculated by the Federal Statistical Office (Statistisches Bundesamt 2012a). The life expectancy data for the East German regions (Bezirke; N=15) in 1968-71 was derived from regional life tables calculated by the statistical office of the GDR (Ministerrat der DDR-Staatliche Zentralverwaltung für Statistik 1973).

In light of the reunification of Germany in 1990 and the large mortality changes in eastern Germany which followed, we provide more detailed mortality data at the district level (NUTS 3; Kreise) for the period 1995-2011. For the analysis, we combined all of the districts which gained or lost territories as a result of reforms in district-level borders; this allowed us to create a dataset of units with timeconstant boundaries for this period $(\mathrm{N}=396)$. Life expectancy was calculated from age-specific population and death counts (data provided by the statistical offices of the Länder; Statistische Ämter des Bundes und der Länder 2014). Unfortunately, due to substantial reforms in the administrative boundaries of the eastern German districts in the period 1990-1994, it was not possible to include these years in our district-level analysis of mortality trends. The GIS shapefiles for the maps were derived from the MPIDR Population History GIS Collection (MPIDR 2014), which offers a series of annual shapefiles with information on the administrative division of Germany over the last 200 years.

\subsection{Methods}

The period life tables were calculated sex-specifically to derive life expectancy at birth. Life expectancy at birth expresses the number of years a newborn can expect to live under the conditions around the time of birth; i.e., if mortality rates did not change over time. Changes in life expectancy over time were decomposed into age group-specific contributions (Preston et al. 2001). The maps displaying the regional life expectancies at birth for men and women show life expectancies classified into six groups according to an equal interval classification.

\section{Results}

\subsection{Life expectancy trends 1910-2010}

Between 1910 and 2010, life expectancy in Germany increased from 47.4 to 77.7 years among men and from 50.7 to 82.7 years among women (Table 1). Table 1 shows life expectancy changes for approximately every decade from 1910 until 2010 (according to data availability). Life expectancy trends between two succeeding time periods are decomposed into age groups, indicating the proportion a specific age group contributed to the life expectancy change. The table shows that in the first half of the century the biggest improvements were mostly clustered among the younger age groups; whereas since the start of the cardiovascular revolution in the 1970s, life expectancy improvements mostly occurred among the older age groups.

Table 1 around here

\subsection{Life expectancy around 1910}

Figure 1 shows regional variation in life expectancy at birth for men and women at our earliest crosssection around 1910. At all of the time points studied, women tended to exhibit smaller regional differences and higher life expectancies than men. However, the mortality hotspots and the regional patterns were generally the same for both sexes (cf. Figure 2 and 3). The regions with comparatively high life expectancies in the period around 1910 were concentrated in the northern and central parts of present-day Germany. These regions include Schleswig-Holstein, Mecklenburg, parts of presentday Lower Saxony and Hessen, as well as some territories in Thuringia. Regions with very low life expectancies include Bavaria in the south-eastern part of present-day western Germany and Silesia in the south-eastern part of the German Empire. 
Figure 1 around here

At the beginning of the $20^{\text {th }}$ century, infectious diseases were still the most important cause-of-death group, and were heavily and directly influenced by contextual conditions. Infant and child mortality determined overall life expectancies levels to a large extent (Omran 1998). As a consequence, we can see many similarities between the regional infant mortality patterns and the regional life expectancy patterns (for maps of infant mortality, see Klüsener et al. 2014). In 1910 in the German Empire, there was a large degree of regional variation in infant mortality levels, with an average of 181 deaths below age one per 1,000 live births among males and of 152 deaths per 1,000 live births among females. Many areas in north-western and central Germany registered less than 100 infant deaths per 1,000 live births. These numbers were close to those of the adjacent Scandinavian countries, which at that time were the European vanguard countries in the longevity revolution. On the other hand, there were Bavarian areas, where more than 300 infants did not survive their first year of life. These levels were among the highest recorded in Europe at that time, and were rather similar to the levels found in eastern and south-eastern European countries such as Russia and Hungary (Klüsener et al. 2014).

The spatial variation in the prevalence of breastfeeding appears to be relevant for understanding the spatial patterns in infant mortality (Kintner 1987). In north-western Germany, almost all children were breastfed. In Bavaria, on the other hand, a large share of children were never breastfed. Feeding infants meal pap and other artificial foods instead of breast milk was a long-standing tradition in parts of German-speaking central Europe which can be traced back to at least the $15^{\text {th }}$ century (Kintner 1985). As a result, a large number of infants died of water-borne diseases such as diarrhoea (Kintner 1987). As breastfeeding also supports the immune systems of infants, the mortality risks of people who were not breastfed as children might have also been affected at later stages in their lives (Klüsener and Scholz 2013). In the two decades following World War I, a spatial convergence in breastfeeding patterns in Germany took place. In the 1930s, for example, almost all of the children in Bavaria were breastfed, a change which may be attributable to information campaigns on the benefits of breastfeeding (Kintner 1985; 1988). Parallel to these developments, spatial variation in infant mortality levels almost disappeared. A direct causal link between the two trends could not, however, be established (Kintner 1988).

Other factors in addition to breastfeeding practices might have affected life expectancy variation at that time. Life expectancy around 1910 shows a positive association with GDP (see Appendix 1). Northern Germany with its harbour towns benefited very early from the accelerating globalisation trends. The densely populated areas of southern Germany offered only limited livelihood opportunities to their people, which is reflected in the large out-migration streams from these regions to the USA in the $19^{\text {th }}$ century (see e.g., Klüsener and Zagheni forthcoming; Knodel 1967). Climatic factors might have influenced harvest variability as a determinant of potential food shortage, as seasonal variation in temperature and annual variation in precipitation increased from the maritime north-western parts to the more continental southern and south-eastern parts of Germany.

\subsection{Mortality decline after World War I}

As in other European countries, more than half of the life expectancy increase in Germany of more than 30 years between 1910-11 and 2009-11 was achieved in the first half of the study period (Vallin and Mesle 2001; Table 1). The mortality decline in the first half of the $20^{\text {th }}$ century was attributable to very large declines in infant and child mortality, and to a much lesser extent to improvements in middle and older ages (Table 1). Advances in the treatment of infectious diseases and hygiene, including the use of antibiotics starting in the 1940s, were the main drivers of mortality declines in the first half of the $20^{\text {th }}$ century (Omran 1998; Vallin and Meslé 2001). 
A further investigation of regional infant mortality rates between 1910 and 1940 shows that at the start of this period, (north-)western German regions such as Hanover and Hessen-Nassau had still had much lower rates than eastern German regions such as Saxony, Mecklenburg-Schwerin, and the Prussian province of Saxony (today Saxony Anhalt); and Bavaria in southern Germany. However, infant mortality rates rapidly converged in the 1920s and 1930s. Remarkably, the biggest improvements appear to have occurred in 1918-1930, a post-war period which was characterised by very unfavourable economic conditions, including hyperinflation in 1923 and the onset of a world economic crisis (data obtained from Statistical Yearbooks of the Germany Empire).

Since the 1950s, life expectancy levels have risen roughly in tandem across the countries of western Europe (Leon 2011; Vallin and Meslé 2001). After World War II, both West and East Germany initially reported very similar improvements in mortality levels (Table 1). During the 1960s, hardly any life expectancy gains were made in either East or West Germany. Improvements in infant and child mortality were partly counterbalanced by mortality increases at older ages due to cardiovascular diseases (Table 1; Nolte et al. 2000a). However, life expectancy in western and eastern European countries started to diverge since the late 1960s, and a similar east-west gap emerged in Germany (Luy 2004; Meslé and Vallin 2002; Nolte et al. 2000a; Vallin and Meslé 2001). This trend was largely attributable to declines in cardiovascular mortality which were much larger in western than in eastern Europe.

\subsection{Life expectancy around 1970}

In Figure 2 we display male and female life expectancy levels around 1970 at the level of the federal states (Bundesländer) of the West German Federal Republic of Germany (FRG) and at the level of the regions (Bezirke) of the German Democratic Republic (GDR), to which we also refer as East Germany. This period approximately marks the beginning of the period of the onset of the cardiovascular revolution in western Europe (Mesle and Vallin 2002). Among women, all of the areas with rather low life expectancy levels were, apart from Saarland, in East Germany (including West Berlin, which belonged to the West German FRG). The highest levels were recorded in the south, particularly in Baden-Württemberg, and in the far north. Among men, the highest life expectancy levels were in the southern part of East Germany (southern Saxony and Thuringia), while the lowest levels were recorded in West Berlin and the two heavily industrialised areas of North Rhine-Westphalia and Saarland. Thus, clear-cut life expectancy differences between East and West Germany were not discernible in the early 1970s, at least among men.

Figure 2 around here

In the GDR, Dresden had the lowest mortality between the 1960s and 1980s; while in the FRG, Baden-Württemberg was consistently among the most advanced regions. Bremen and Hamburg were not able to maintain their initial favourable positions (Casper and Herrmann 1990; Statistisches Bundesamt 2006). Increases in life expectancy at birth were small in the GDR Bezirke, and were much larger in the FRG Länder. Within East Germany, the regions which had higher mortality initially experienced the largest mortality declines over time (Casper and Herrmann 1990). Similar trends have also been observed in other European countries (Valkonen 2001).

In the literature, these regional mortality differences in the period around 1970 were mainly attributed to medical care and environmental pollution. Infant mortality is sensitive to the availability of high-quality medical care. Around 1970, infant mortality was higher in West than in East Germany, although this discrepancy may have been related to differences in reporting practices (Luy 2004). At this time, infant mortality was still an important factor in regional variation in life expectancy. A study conducted by the GDR government uncovered differences in infant mortality rates at the district level (Kreise) in the GDR in 1966. Higher infant mortality rates were related to a lower quality of paediatric care (Institut für Planung und Organisation des Gesundheitsschutzes 1968). Apart from the influence of health care quality on regional mortality differences, determinants of regional mortality 
differences were hardly discussed in the GDR. For the FRG, a relationship between infant mortality and medical care was mentioned, but it was not documented with empirical evidence (Heins 1985).

Meslé and Vallin (2002, p. 182-183) noted that the communist regimes relied heavily on "the centralised administration of modern health care, whereas the struggle against cardiovascular diseases, unlike that against infectious diseases, requires important changes in individual behaviour and the active participation of citizens in the management of their own health care." Reducing mortality from cardiovascular diseases also requires substantial investments in the health care system and medical technologies, for which the East German government lacked the necessary resources. The GDR health care system focused on the health of children, mothers, and workers; which resulted in low mortality rates among children in the early years of the GDR (Nolte et al. 2000a).

Other factors with potential relevance for regional mortality patterns around 1970 included variation in environmental pollution levels and in socioeconomic conditions. In the GDR, a higher burden of emissions was associated with higher mortality, particularly cardiovascular mortality. However, there were also regions in the GDR which had very little pollution but still had high mortality rates, such as the northern Bezirke (Vogt 2013). Nonetheless, the mortality reductions which occurred after reunification can be attributed in part to improvements in environmental conditions due to the cleaning up of industrial sites and the dismantling of heavy industries in eastern Germany (Black Triangle Region; Middle German Chemical Triangle) (Heinrich 1995; Heinrich et al. 1999; Vogt 2013; Wichmann and Müller-Nordhorn et al. 2004).

In the FRG, excess mortality was found in the high-density coal and steel industry regions of the Ruhr (the central part of North Rhine-Westphalia) and Saarland as, as well as in West Berlin and in several rural and remote regions (see also Figure 3). Excess mortality in the industrialised regions stemmed from cancer of the respiratory organs, diseases of the digestive system, bronchitis, and liver cirrhosis. This provides some evidence of a relationship between environmental (and social) burden and elevated mortality risks (Gatzweiler and Stiens 1982).

In areas which were industrialised early, such as the mining regions in North Rhine-Westphalia and Saarland, and which had thus suffered from substantial pollution, these negative effects were reduced starting the 1950s and 1960s, partly as a result of the introduction of higher environmental standards, and partly because these heavy industries declined in importance. However, as the environmental burden cannot account for all of the excess mortality found in certain rural regions of West Germany, it has been suggested that other determinants must have been partly responsible. This includes that high-mortality regions were also experiencing social challenges and high levels of social inequality (Gatzweiler and Stiens 1982; van Poppel 1981).

\subsection{Emergence of the east-west life expectancy gap}

The emergence of the east-west life expectancy gap starting in the 1970s, and its subsequent reduction since the 1990s, are issues that have been frequently studied and discussed elsewhere (Diehl 2008; Kibele 2012; Luy 2004; Nolte et al. 2000a). Thus, we discuss it only briefly here. A large portion of the east-west life expectancy gap was attributable to higher mortality in the GDR from cardiovascular and respiratory diseases among people aged 45+, but also from injuries at younger ages (Table 1; Kibele 2012; Nolte et al. 2000a). Health care and economic conditions, as well as lifestyle factors and a greater environmental burden, were among the most important determinants of higher mortality in East Germany (Diehl 2008; Luy 2004; Myrskylä and Scholz 2013).

\subsection{Life expectancy after reunification}

In the period between 1970 and 1990, the positive relationship between regional life expectancy patterns and regional economic conditions strengthened substantially within West Germany (cf. Kuhn et al. 2006). This development was also accompanied by a widening of the life expectancy gap 
between East and West Germany, which occurred as the economic development levels of the two countries were diverging. This pattern changed soon after reunification, though immediately after 1989, a short-term rise in male mortality in eastern Germany was recorded. This was largely attributable to increases in traffic-related mortality among young men (Nolte et al. 2000b; Winston et al. 1999).

Life expectancy gains in eastern Germany were much stronger than in western Germany during the 1990s, which influenced regional mortality patterns as well. Nevertheless, large parts of eastern Germany continued to have relatively high mortality levels in the 1990s (Figure 3). East-west life expectancy differences in the mid-1990s were mainly attributable to excess cardiovascular mortality among people aged $60+$. Among men, there was also considerable excess mortality at younger ages due to external causes and diseases of the digestive system (Nolte et al. 2000b).

Figure 3 around here

Eastern Germans of all ages benefited from the large mortality declines after reunification. However, eastern German men of middle adult and older ages and eastern German women of older ages registered the greatest improvements (Luy 2004; Nolte et al. 2000b; Table 1). Survival improvements in the eastern German districts were attributable in large part to sharp declines in deaths from heart disease and traffic-related accidents. There were also substantial reductions in cancer mortality among men and in alcohol-related mortality among women. Among the eastern German regions, above-average gains were documented in Saxony, Thuringia, and the Brandenburg districts surrounding Berlin, which received substantial in-migration from Berlin due to suburbanisation processes.

Within western Germany, regional variation in life expectancy levels was quite stable in the 1990s and 2000s. The areas with the highest life expectancies were clustered in Baden-Württemberg and southern Bavaria in southern Germany. However, there were also some mortality hotspots in western Germany which reported mortality levels as high as those of the worst areas in eastern Germany. These western German mortality hotspots were mostly concentrated in economically disadvantaged areas, including Saarland and adjacent areas of Rhineland-Palatinate, parts of the Ruhr areas, the north-eastern part of Bavaria, and a few scattered districts in northern Germany, including all of the North Sea harbour towns (Figure 3). Districts in western Germany which had small life expectancy gains also had slow declines in respiratory mortality, male lung cancer mortality, and traffic-related mortality.

Today, the regional distribution of cardiovascular mortality dominates the regional mortality patterns, but the spatial patterns of cardiovascular mortality are also similar to those of alcoholrelated and male cancer mortality. Among women, mortality levels in regions such as Saxony have declined to the levels reported in western Germany; while among men the differences between eastern and western Germany persist. These gender differences found in the regional life expectancy patterns are largely attributable to behaviour-related causes of death, such as lung cancer, traffic accidents, and alcohol consumption (Kibele 2012).

Urban-rural life expectancy differences are small and diminishing (Kibele 2012; Valkonen 2001). Towards the end of the $20^{\text {th }}$ century and the beginning of the $21^{\text {st }}$ century, life expectancy in western Germany tends to be lower in urban areas, while eastern Germany exhibits a reverse pattern. Rural areas in the entire country have excess mortality at young adult ages due to traffic-related mortality (Kibele 2012).

For the most recent periods, explanations of regional mortality patterns centre around regional socioeconomic conditions. Virtually all of the studies on regional mortality from the 1970s up until today have found an association between high mortality and socioeconomic deprivation in western Germany's regions. Investigations of the relationship between mortality in the German NUTS-3 districts and contextual conditions have revealed a particularly strong association with regional socioeconomic conditions (Brzoska and Razum 2008), even when compared with other factors like 
the physical environment or health care (Latzitis et al. 2011). The strong role of socioeconomic mortality determinants has also been confirmed by several studies contrasting variation across districts or municipalities within a specific federal state (e.g., Kuhn et al. 2006; Maier et al. 2012; Strohmeier et al 2007). Maier et al. (2012) found an association between an index of multiple deprivation and mortality across the Bavarian municipalities. Most of the index's domains on socioeconomic conditions-i.e., social capital, physical environment and safety-were found to be significantly and independently correlated with mortality, especially the socioeconomic domains. In North Rhine-Westphalia, life expectancy at birth, avoidable deaths, and other mortality indicators were shown to be related to socioeconomic conditions in the districts; only a few specific mortality indicators, like infant mortality and female breast cancer, did not show such a relationship (Strohmeier et al. 2007).

A study which simultaneously investigated the determinants of life expectancy differences between districts, as well as of life expectancy changes over time, revealed that life expectancy differences between the regions were largely explained by income, based on indicators reflecting the effective health policy implementation derived from deaths amenable to health care and health policy, and the educational level. The indicators reflecting changes in GDP per capita and the average living space explained life expectancy increases over time. East-west differences in district-level life expectancy could be traced back almost entirely to differences in socioeconomic conditions (Kibele 2012).

Improvements in medical care and disease prevention were crucial factors in the decline in mortality levels, and contributed significantly to the mortality differences between the FRG and the GDR (Nolte et al. 2002). The fact that German regulations mandate equal quality and accessibility of health care across the states affects the spatial dimension. Plans for allocating health care services across Germany take into account the demographic composition in the regions, although not the morbidity level. For ambulatory care, general practitioners, but not medical specialists, are distributed equally across the regions (Ozegowski and Sundmacher 2012). Generally, there are more physicians in wealthier areas and in the cities. People living in cities may also benefit from more specialised care and shorter distances to hospitals. Several regions of Germany register a severe shortage in general practitioners. This includes particularly rural areas in eastern Germany (Kopetsch 2010).

Empirical studies on the (ecological) association between regional mortality and indicators of health care provision have shown that the relationship between regional mortality and the number of physicians or hospital beds per capita is small, or is even counterintuitive (Kibele 2012; Kuhn et al. 2006; Latzitis et al. 2011). When the concept of avoidable mortality-i.e., mortality which could be prevented with timely and efficient health care-was used as a measure of health care performance and quality of health care, a high correlation with life expectancy across the regions was found (Kibele 2012; Sundmacher et al. 2012). Thus, while in the cross-section, the role of the health care system in explaining regional mortality patterns is not straightforward, it appears to be important in explaining mortality changes over time (cf. Omran 1998; Meslé and Vallin 2002; Nolte et al. 2002).

Several studies have attempted to identify the impact of environmental pollution on regional mortality differences, but with inconclusive results. While an association between improvements in air pollution after reunification and life expectancy gains and declines in cardiovascular mortality has been found, the cross-sectional association between higher pollution and lower life expectancy did not uniformly hold (Vogt 2013). Exposure to pollution was found to be higher among people of lower socioeconomic status. Regions with specific industries, such as coal, steel, and mining, are more likely to have to detrimental environmental conditions (Gatzweiler and Stiens 1982). It appears that the many facets of detrimental environmental pollution are hard to capture at the regional level, and that it is more appropriate to take a small-area perspective and include individual characteristics.

In recent years, a number of health studies combining individual-level data with district-level information have been carried out for Germany. These studies concluded that regional differences in 
population composition-often due to socioeconomic factors-explain a large part of regional variation. However, an independent effect of regional conditions (mainly of a socioeconomic nature) on health outcomes remained after controlling for population composition. This has been shown for self-rated health (Diehl and Schneider 2011), subjective physical health (Voigtländer et al. 2010), and long-standing illness among resettlers (Aussiedler) (Kreft and Doblhammer 2012). For old-age mortality, such regional effects have been identified for western but not for eastern Germany (Kibele 2014).

\section{Conclusion}

In this paper we adopted a long-term perspective to study regional mortality disparities in Germany, following these differences over the course of a full century. Our empirical analysis focused on spatial and temporal variation in life expectancy at birth as an indicator of population health and survival conditions. We were able to identify both continuities and discontinuities in the spatial patterns. A major discontinuity is that northern Germany, and particularly the north-western part of the country, had been at the forefront of the longevity revolution at the beginning of the $20^{\text {th }}$ century, but had forfeited this position to southern Germany by the end or our study period. Southern Germany, on the other hand, went from being one of the most disadvantaged areas in terms of mortality levels to being the region with the highest life expectancies in Germany. This trend generally seems to correspond with long-term shifts in regional variation in economic conditions. A continuity, at least among women, seems to be that eastern Germany was lagging behind western Germany-although the southern part of eastern Germany, and particularly Saxony, represented an exception to this general pattern, both in 1970 and in the most recent years.

The existing research on determinants which might explain regional mortality variation within Germany in different time periods in the $20^{\text {th }}$ century suggests that over time, there were substantial changes in the factors which predominantly contributed to spatial life expectancy disparities. This assumption is in line with the theoretical considerations of Omran (1998). The relationship between regional economic development and mortality appears to be strong. Although the results of our analysis indicate that there was already a weak positive association between economic development and mortality at the beginning of the $20^{\text {th }}$ century, it appears that this relationship strengthened over time (cf. Bengtsson and van Poppel 2011). At the beginning of the $20^{\text {th }}$ century, mortality patterns were also influenced by variation in cultural practices. In addition, most areas that industrialised early were characterised not only by elevated levels of economic development, but also by high levels of pollution and a large share of people working in hazardous occupations. It is likely that the substantial reduction in pollution levels and occupational health risks which contributed to elevated mortality risks in highly developed areas in turn contributed to the strengthening of the association between economic development and life expectancy levels across regions. This shift could have occurred parallel to a general shift from a dominance of environmental or contextual influences in shaping regional variation in mortality to a dominance of individuals' health behaviour and social status (cf. Kuhn et al. 2006). The containment of infectious diseases as dominant causes of deaths contributed to this general shift and to make survival outcomes socially more selective (Bengtsson and van Poppel 2011).

The limitations of our study include the fact that the descriptive aggregate-level analysis was complicated by changes in the administrative division Germany experienced over the last 110 years, including the loss of the territories east of the Oder-Neisse line. Thus, for many parts of Germany it was not possible to conduct the analysis based on time-constant areas, which would have allowed us to study regional trend data. In addition, the level of spatial detail at which data could be obtained varied over time, as small-area mortality data was readily available for the most recent decades only. Moreover, as we were working with aggregate-level information, we were not able to look into the role of compositional and contextual effects and the potential influences of selective migration on 
the observed pattern. Selective migration can reinforce regional mortality patterns by attracting migrants to prosperous regions which already have lower mortality, as migrants are usually healthier (Boyle 2004; Luy and Caselli 2007).

To further improve our understanding of long-term regional mortality trends in Germany, we see a number of potential avenues for future research. As Germany is situated at the centre of Europe, it would be interesting to consider in an extended analysis regional mortality trends in neighbouring countries as well (cf. Shaw et al. 2000). This would enable us to determine whether the German trends in regional mortality variation are part of larger spatial variation pattern. In addition, it would allow us to investigate whether mortality improvements in German regions and the adjacent regions in neighbouring countries took place at the same time and at a similar pace, or whether there are substantial differences. As it appears that regional mortality disparities cannot be fully explained by the compositional characteristics of populations alone, it would be interesting to perform case studies on regions with distinctive mortality conditions. This could, for example, be an in-depth study of regions experiencing low mortality despite adverse conditions, or vice versa (Cairns et al. 2012); or the exploration of the effect of selective migration in a study with a longitudinal design. The study of various diseases and health outcomes, including wellbeing from a regional perspective, could help us to further improve our understanding of the causal pathways between regional conditions and population health. This could also contribute to find explanations of why regional patterns in health outcomes other than mortality differ in some cases from the regional mortality patterns (Diehl and Schneider 2011; Kreft forthcoming). In addition, such findings could be of high relevance for decisions regarding the allocation of future health care investments. 


\section{References}

1. Adler, N. E., and Ostrove, J. M. 1999. Socioeconomic Status and Health: What We Know and What We Don't. Annals of the New York Academy of Sciences 896:3-15.

2. Barbujani, G., and R. R. Sokal. 1990. Zones of sharp genetic change in Europe are also linguistic boundaries. Proceedings of the National Academy of Sciences of the United States of America 87:1816-1819.

3. Bengtsson, T., and F. van Poppel. 2011. Socioeconomic inequalities in death from past to present: An introduction. Explorations in Economic History 48:343-356.

4. Bonneux, L. G., C. C. Huisman, and J. A. de Beer. 2010. Mortality in 272 European regions, 2002-2004. An update. European Journal of Epidemiology 25:77-85.

5. Bourdieu, P., and L. J. D. Wacquant. 1992. An Invitation to Reflexive Sociology. Chicago: University of Chicago Press.

6. Boyle, P. 2004. Population geography: migration and inequalities in mortality and morbidity. Progress in Human Geography 28:767-776.

7. Brzoska, P., and O. Razum. 2008. Privatverschuldung und Mortalität: Untersuchung auf Ebene der Kreise und kreisfreien Städte Deutschlands. Gesundheitswesen 70:387-392.

8. Burger, O., A. Baudisch, and J. W. Vaupel. 2012. Human mortality improvement in evolutionary context. Proceedings of the National Academy of Sciences of the United States of America 109:18210-18214.

9. Cairns, J., S. Curtis, and C. Bambra. 2012. Defying deprivation: A cross-sectional analysis of area level health resilience in England. Health \& Place 18:928-933.

10. Casper, W., and S. Herrmann. 1990. Bevölkerung. In Das GesundheitswesenJahresgesundheitsbericht 1989 für das Gebiet der ehemaligen DDR, Eds. D. Bardehle, and W. Casper, 1-43. Ärztebuch Verlag GmbH Berlin/Medizinischer Fachverlag Leipzig.

11. Christensen, K., and J. W. Vaupel. 1996. Determinants of longevity: genetic, environmental and medical factors. Journal of Internal Medicine 240:333-341.

12. Cromm, J., and R. Scholz (Eds.) (2002). Regionale Sterblichkeit in Deutschland. Augsburg, Göttingen: WiSoMed.

13. Cummins, S., S. Curtis, A. V. Diez-Roux, and S. Macintyre. 2007. Understanding and representing 'place' in health research: a relational approach. Social Science \& Medicine 65: $1825-1838$.

14. Diehl, K. 2008. Mögliche Faktoren für die rasche Reduktion der ostdeutschen Übersterblichkeit nach der Wiedervereinigung. Warum leben Ostdeutsche seit der Wiedervereinigung länger? Zeitschrift für Bevölkerungswissenschaft 33:89-110.

15. Diehl, K., and S. Schneider. 2011. How relevant are district characteristics in explaining subjective health in Germany?-A multilevel analysis. Social Science \& Medicine 72:12051210.

16. Diez Roux, A. V. 2002. A glossary for multilevel analysis. Journal of Epidemiology and Community Health 56:588-594.

17. Gatrell, A. C. 2002. Geographies of health: an introduction. Blackwell Publishing.

18. Gatzweiler, H.-P., and G. Stiens. 1982. Regionale Mortalitätsunterschiede in der Bundesrepublik Deutschland-Daten und Hypothesen. Jahrbuch für Regionalwissenschaft 3: 36-63.

19. Harvey, D. 1990. The condition of postmodernity: An enquiry into the origins of cultural change. Oxford: Oxford University Press.

20. Heinrich, J., B. Hoelscher, M. Wjst, B. Ritz, J. Cyrys, and H.-E. Wichmann. 1999. Respiratory Diseases and Allergies in Two Polluted Areas in East Germany. Environmental Health Perspectives 107: 53-62.

21. Heins, F. 1985. Zur Beobachtung regionaler Unterschiede der Morbidität in der Bundesrepublik Deutschland. Informationen zur Raumentwicklung 3-4:221-235. 
22. Hoffmann, W. G., J. H. Müller. 1959 [2005]. Das Deutsche Volkseinkommen in ausgewählten Bundesstaaten 1851-1913. GESIS Köln, Deutschland ZA8224 Data file version 1.0.0.

23. Howe, G. M. 1986. Does it matter where I live? Transactions of the Institute of British Geographers 11:387-411.

24. Institut für Planung und Organisation des Gesundheitsschutzes, Abteilung Statistik/EDV (Ed.). 1968. Das Gesundheitswesen der Deutschen Demokratischen Republik 1968. Berlin

25. Johansson, S. R., and A. B. Kasakoff. 2000. Mortality History and the Misleading Mean. Historical Methods: A Journal of Quantitative and Interdisciplinary History 33:56-58.

26. Kawachi, I., and L. F. Berkman. 2003. Neighborhoods and health. Oxford University Press.

27. Kibele, E. U. B. 2012. Regional mortality differences in Germany. Springer.

28. Kibele, E. U. B. 2014. Individual- and area-level effects on mortality risk in Germany, both East and West, among male Germans aged 65+. International Journal of Public Health 59:439-448.

29. Kibele, E., and F. Janssen 2013. Distortion of regional old-age mortality due to late-life migration in the Netherlands? Demographic Research 29:105-132.

30. Kickbusch, I. 2003. The Contribution of the World Health Organization to a New Public Health and Health Promotion. American Journal of Public Health 93:383-388.

31. Kintner, H. J. 1985. Trends and regional differences in breastfeeding in Germany. Journal of Family History 10:163-182.

32. Kintner, H. J. 1987. The impact of breastfeeding patterns on regional differences in infant mortality in Germany, 1910. European Journal of Population 3:233-261.

33. Kintner, H. J. 1988. Determinants of temporal and areal variation in infant mortality in Germany, 1871-1933. Demography 25:597-609.

34. Klüsener, S. and R. D. Scholz. 2013. Regional hot spots of exceptional longevity in Germany. Vienna Yearbook of Population Research 11:157-182.

35. Klüsener, S., and E. Zagheni. 2014. The East-West gradient in spatial population development within Germany: Temporary GDR legacy vs. longstanding spatial disparities. Historical Methods 47:167-179.

36. Klüsener, S., I. Devos, P. Ekamper, I. Gregory, S. Gruber, J. Martí-Henneberg, F. van Poppel, L. Silveira, and A. Solli. 2014. Spatial inequalities in infant survival at an early stage of the longevity revolution: A pan-European view across 5000+ regions and localities in 1910 Demographic Research 30:1849-1864.

37. Knodel, J. 1967. Law, marriage and illegitimacy in nineteenth-century Germany. Population Studies 20:279-294.

38. Koch, B., M. Wendt, C. Lackner, and F.-W. Ahnefeld. 2008. Herausforderungen an die Notfallversorgung der Zukunft: „Regional Health Care“ (RHC). Notfall + Rettungsmedizin, 11:491-499.

39. Kopetsch, T. 2010. Dem deutschen Gesundheitswesen gehen die Ärzte aus! Studie zur Altersstruktur und Arztzahlentwicklung. Berlin: Bundesärztekammer und Kassenärztliche Bundesvereinigung.

40. Kreft, D. forthcoming. Spatial Patterns in German Long-term Care and their Relationship with Socioeconomic Factors. In Health among the Elderly in Germany: New Evidence on Disease, Disability and Care Need, Ed. Doblhammer, G. Opladen: Barbara Budrich.

41. Kreft, D., and G. Doblhammer. 2012. Contextual and individual determinants of health among Aussiedler and native Germans. Health \& Place 18:1046-1055.

42. Kuh, D., Y. Ben-Shlomo, and S. Ezra (Eds.). 2004. A life course approach to chronic disease epidemiology. Oxford University Press.

43. Kuhn, J., A. Zirngibl, M. Wildner, W. H. Caselmann, and G. Kerscher. 2006. Regionale Sterblichkeitsunterschiede in Bayern. Gesundheitswesen 68:551-556.

44. Lalonde, M. A. 1974. A New Perspective on the Health of Canadians. Ottawa, Ontario, Canada: Information Canada. 
45. Lao O., T. T. Lu, M. Nothnagel, O. Junge, S. Freitag-Wolf, A. Caliebe, M. Balascakova, J. Bertranpetit, L.A. Bindoff, D. Comas, G. Holmlund, A. Kouvatsi, M. Macek, I. Mollet, W. Parson, J. Palo, R. Ploski, A. Sajantila, A. Tagliabracci, U. Gether, T. Werge, F. Rivadeneira, A. Hofman, A.G. Uitterlinden, C. Gieger, H.-E. Wichmann, A. Rüther, S. Schreiber, C. Becker, P. Nürnberg, M.R. Nelson, M. Krawczak, and M. Kayser. 2008. Correlation between genetic and geographic structure in Europe. Current Biology 18:1241-1248.

46. Latzitis, N., L. Sundmacher, and R. Busse. 2011. Regionale Unterschiede der Lebenserwartung in Deutschland auf Ebene der Kreise und kreisfreien Städte und deren möglichen Determinanten. Gesundheitswesen 73:217-228.

47. Lee, W. R., and M. S. Schneider. 2005. Amtliche Statistik zwischen Staat und Wissenschaft, 1872-1939. In Das Konstrukt "Bevölkerung" vor, im und nach dem „Dritten Reich", Eds. R. Mackensen, J. Reulecke 50-91. Wiesbaden, VS Verlag für Sozialwissenschaften.

48. Leon, D. A. 2011. Trends in European life expectancy: a salutary view. International Journal of Epidemiology 40:271-277.

49. Luy, M. 2002. Die geschlechtsspezifischen Sterblichkeitsunterschiede-Zeit für eine Zwischenbilanz. Zeitschrift für Gerontologie und Geriatrie 35:412-429.

50. Luy, M. 2004. Verschiedene Aspekte der Sterblichkeitsentwicklung in Deutschland von 19502000. Zeitschrift für Bevölkerungswissenschaft 29:3-62.

51. Luy, M., and G. Caselli. 2007. The impact of a migration-caused selection effect on regional mortality differences in Italy and Germany. Genus 63:33-64.

52. Maier, W., J. Fairburn, and A. Mielck. 2012. Regionale Deprivation und Mortalität in Bayern. Entwicklung eines ,Index Multipler Deprivation' auf Gemeindeebene. Gesundheitswesen 74:416-425.

53. Meijer, M., J. Röhl, K. Bloomfield, and U. Grittner. 2012. Do neighborhoods affect individual mortality? A systematic review and meta-analysis of multilevel studies. Social Science \& Medicine 74:1204-1212.

54. Meslé, F., and J. Vallin. 2002. Mortality in Europe: The divergence between East and West. Population (English Edition) 57:157-197.

55. Ministerrat der DDR-Staatliche Zentralverwaltung für Statistik. 1973. Sterbetafeln 1968/71 $D D R$, Bezirke, Großstädte. Unpublished.

56. MPIDR [Max Planck Institute for Demographic Research]. 2014. MPIDR Population History GIS Collection. Rostock: MPIDR.

57. Müller-Nordhorn, J., K. Rossnagel, W. May, and S. N. Willich. 2004. Regional variation and time trends in mortality from ischaemic heart disease: East and West Germany 10 years after reunification. Journal of Epidemiology and Community Health 58:481-485.

58. Myrskylä, M., and R. Scholz. 2013. Reversing East-West mortality difference among German women, and the role of smoking. International Journal of Epidemiology 42:549-558.

59. Nolte, E., R. Scholz, V. Shkolnikov, and M. McKee. 2002. The contribution of medical care to changing life expectancy in Germany and Poland. Social Science \& Medicine 55:1905-1921.

60. Nolte, E., V. Shkolnikov, and M. McKee. 2000a. Changing mortality patterns in East and West Germany and Poland. I: long term trends (1960-1997). Journal of Epidemiology and Community Health 54:890-898.

61. Nolte, E., V. Shkolnikov, and M. McKee. 2000b. Changing mortality patterns in East and West Germany and Poland. II: Short-term trends during transition and in the 1990s. Journal of Epidemiology and Community Health 54:899-906.

62. Nolting, H.-D., and K. Zich. 2014. Regionale Versorgungsunterschiede in Deutschland. Public Health Forum 22:9.e1-9.e4.

63. Omran, A. R. 1998. The epidemiologic transition theory revisited thirty years later. World Health Statistics Quarterly 51:99-119.

64. Ozegowski, S., and L. Sundmacher. 2012. Wie „bedarfsgerecht “ist die Bedarfsplanung? Eine Analyse der regionalen Verteilung der vertragsärztlichen Versorgung. Gesundheitswesen 74:618-626. 
65. Preston, S. H., P. Heuveline, and M. Guillot. 2001. Demography: measuring and modeling population processes. Blackwell Publishers

66. Riva, M., L. Gauvin, and T. A. Barnett. 2007. Toward the next generation of research into small area effects on health: a synthesis of multilevel investigations published since July 1998. Journal of Epidemiology and Community Health 61:853-861.

67. Robine, J. M., Y. Saito, and C. Jagger. 2009. The relationship between longevity and healthy life expectancy. Quality in Ageing and Older Adults 10:5-14.

68. Schofield, R., D. Reher, and A. Bideau. 1991. The decline of mortality in Europe. Oxford: Oxford University Press.

69. Shaw, M., D. Dorling, R. Mitchell. 2002. Health, Place and Society. Pearson.

70. Shaw, M., S. Orford, N. Brimblecombe, and D. Dorling. 2000. Widening inequality in mortality between 160 regions of 15 European countries in the early 1990s. Social Science \& Medicine 50:1047-1058.

71. Statistische Ämter des Bundes und der Länder. 2014. Regionaldatenbank Deutschland.

72. Statistisches Bundesamt. 2006. Periodensterbetafeln für Deutschland. Allgemeine und abgekürzte Sterbetafeln. 1871/1881 bis 2003/2005. Wiesbaden: Statistisches Bundesamt.

73. Statistisches Bundesamt. 2012a. Periodensterbetafeln für Deutschland. Allgemeine Sterbetafeln, abgekürzte Sterbetafeln und Sterbetafeln. 1871/1881 bis 2008/2010. Wiesbaden: Statistisches Bundesamt.

74. Statistisches Bundesamt. 2012b. Periodensterbetafeln für Deutschland. Früheres Bundesgebiet, neue Länder sowie die Bundesländer. 2009/2011. Wiesbaden: Statistisches Bundesamt.

75. Statistisches Reichsamt. 1918. Bewegung der Bevölkerung im Jahre 1913. Verlag von Puttkammer und Mühlbrecht. Statistik des Deutschen Reichs, Band 275.

76. Strohmeier, K. P., A. Schultz, D. Bardehle, R. Annuss, and A. Lenz. 2007. Sozialräumliche Clusteranalyse der Kreise und kreisfreien Städte und Gesundheitsindikatoren in NRW. Gesundheitswesen 69:26-33.

77. Sundmacher, L., M. D. Gaskins, K. Hofmann, and R. Busse. 2012. Spatial distribution of avoidable cancer deaths in Germany. Journal of Public Health 20:279-288.

78. Tunstall, H. V. Z., M. Shaw, and D. Dorling. 2004. Places and health. Journal of Epidemiology and Community Health 58:6-10.

79. Valkonen, T. 2001. Trends in differential mortality in European countries. In Trends in mortality and differential mortality, Eds. J. Vallin and F. Meslé, 185-321. Strasbourg: Council of Europe Publishing.

80. Vallin J., and F. Meslé. 2001. Trends in mortality in Europe since 1950: age- sex- and causespecific mortality. In Trends in mortality and differential mortality, Eds. J. Vallin and F. Meslé, 31-184. Strasbourg: Council of Europe Publishing.

81. Van Poppel, F. 1981. Regional mortality differences in western Europe: A review of the situation in the seventies. Social Science \& Medicine Part D: Medical Geography 15:341-352.

82. Van Poppel, F. 1992. Religion and Health: Catholicism and Regional Mortality Differences in Nineteenth-Century Netherlands. Social History of Medicine 5:229-253.

83. Van Poppel, F., and C. van der Heijden. 1997. The effects of water supply on infant and childhood mortality: a review of historical evidence. Health Transition Review 7:113-148.

84. Vogt, T. C. 2013. Money or Medicine? The importance of rising pension income and modern health care for old age survival in the natural experiment setting of the German reunification. $\mathrm{PhD}$ thesis University of Rostock, Faculty of Economic and Social Sciences.

85. Voigtländer, S., U. Berger, and O. Razum. 2010. The impact of regional and neighbourhood deprivation on physical health in Germany: a multilevel study. BMC Public Health 10:403.

86. Wichmann, H.-E., and J. Heinrich. 1995. Health Effects of High Level Exposure to Traditional Pollutants in East Germany-Review and Ongoing Research. Environmental Health Perspectives 103:29-35. 
87. Winston, F. K., C. Rineer, R. Menon, and S. P. Baker. 1999. The carnage wrought by major economic change: ecological study of traffic related mortality and the reunification of Germany. British Medical Journal 318:1647-1649.

88. Wolleswinkel-van den Bosch, J. 1998. The Epidemiological Transition in The Netherlands. PhD thesis Erasmus University Rotterdam.

89. Woods, R. 2003. Urban-Rural Mortality Differentials: An Unresolved Debate. Population and Development Review 29:29-46. 
Table 1: Decomposition of trends in life expectancy at birth (LE) between 1910-11 and 2009-11 by age groups; contributions are shown as a percentage of overall change in life expectancy

\begin{tabular}{|c|c|c|c|c|c|c|c|c|c|c|c|c|c|c|}
\hline \multirow{2}{*}{$\begin{array}{l}\text { Men } \\
\text { Time period }\end{array}$} & \multicolumn{3}{|c|}{ German Empire } & \multicolumn{5}{|c|}{ FRG/western Germany } & \multicolumn{5}{|c|}{ GDR/eastern Germany } & \multirow{2}{*}{$\begin{array}{l}\text { Ger } \\
\text { man } \\
y\end{array}$} \\
\hline & 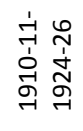 & \begin{tabular}{l}
$\stackrel{\dot{\sim}}{\sim}$ \\
\multirow{1}{*}{} \\
$\stackrel{\sim}{\sim}$ \\
$\stackrel{\sim}{\sim}$
\end{tabular} & 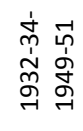 & 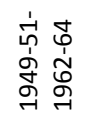 & 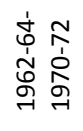 & 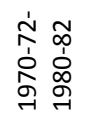 & 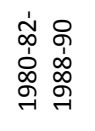 & 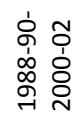 & 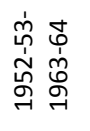 & 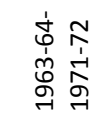 & 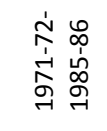 & 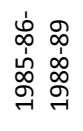 & 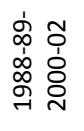 & \\
\hline LE start & 47.4 & 56.0 & 59.9 & 64.6 & 67.3 & 67.4 & 70.2 & 72.5 & 65.1 & 68.3 & 68.5 & & 70.0 & 75.4 \\
\hline LE end & 56.0 & 59.9 & 64.6 & 67.3 & 67.4 & 70.2 & 72.5 & 75.7 & 3.21 & 0.19 & 1.17 & 0.39 & 4.08 & 2.34 \\
\hline $\begin{array}{l}\text { Change in LE } \\
\text { Average annual } \\
\text { change in LE }\end{array}$ & 8.56 & 3.89 & 0.28 & 2.72 & 0.13 & 2.77 & 2.37 & 0.26 & 0.29 & 0.02 & 0.08 & 0.13 & 0.33 & 0.26 \\
\hline Age group & Decom & ositio & contri & tion of ag & group & to chan & ges in & xpectan & cy (in \%) & & & & & \\
\hline 0 & 48.6 & 50.2 & 34.4 & 79.9 & 230.0 & 33.1 & 14.4 & 8.7 & 61,1 & 454.5 & 50.4 & 35.7 & 8.7 & 2.2 \\
\hline $1-14$ & 21.6 & 14.7 & 21.3 & 17.5 & 45.3 & 8.6 & 5.5 & 3.5 & 12,4 & 84.2 & 13.4 & 18.2 & 3.9 & 1.8 \\
\hline $15-29$ & 3.0 & 16.3 & 11.0 & 8.8 & -78.9 & 10.0 & 11.2 & 5.0 & 3,0 & 45.1 & 11.4 & 23.5 & 3.3 & 8.5 \\
\hline $30-44$ & 8.1 & 5.2 & 11.1 & 10.4 & -46.0 & 7.2 & 8.5 & 8.2 & 6,3 & -46.4 & 3.4 & -19.4 & 7.5 & 10.7 \\
\hline $45-59$ & 10.9 & 5.6 & 6.9 & 3.8 & 26.4 & 7.5 & 19.1 & 17.5 & 3,9 & 53.7 & -13.3 & -18.8 & 20.8 & 15.9 \\
\hline $60-74$ & 6.4 & 6.7 & 11.1 & -19.9 & -54.0 & 26.9 & 27.8 & 34.0 & $-0,8$ & -223.1 & 31.7 & 25.3 & 35.8 & 36.8 \\
\hline $75+$ & 1.5 & 1.3 & 4.3 & -0.5 & -22.9 & 6.6 & 13.4 & 23.2 & 14,2 & -268.0 & 3.1 & 35.4 & 20.0 & 24.1 \\
\hline
\end{tabular}

\begin{tabular}{|c|c|c|c|c|c|c|c|c|c|c|c|c|c|c|}
\hline \multirow{2}{*}{$\begin{array}{l}\text { Women } \\
\text { Time period }\end{array}$} & \multicolumn{3}{|c|}{ German Empire } & \multicolumn{5}{|c|}{ FRG/western Germany } & \multicolumn{5}{|c|}{ GDR/eastern Germany } & \multirow{2}{*}{ 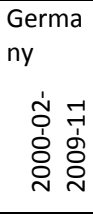 } \\
\hline & 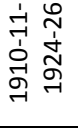 & 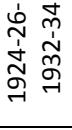 & 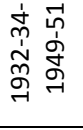 & 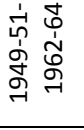 & 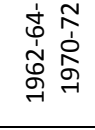 & 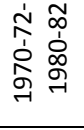 & 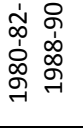 & 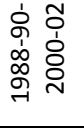 & 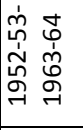 & 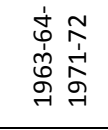 & 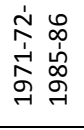 & 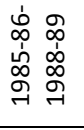 & 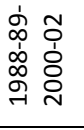 & \\
\hline LE start & 50.7 & 58.8 & 62.8 & 68.5 & 73.0 & 73.8 & 76.9 & 79.0 & 69.1 & 73.3 & 73.7 & 75.5 & 76.2 & 81.2 \\
\hline LE end & 58.8 & 62.8 & 68.5 & 73.0 & 73.8 & 76.9 & 79.0 & 81.4 & 73.3 & 73.7 & 75.5 & 76.2 & 80.8 & 82.7 \\
\hline Change in LE & 8.15 & 3.99 & 5.67 & 4.55 & 0.79 & 3.02 & 2.13 & 2.37 & 4.27 & 0.39 & 1.75 & 0.75 & 4.55 & 1.51 \\
\hline $\begin{array}{l}\text { Average annu } \\
\text { change in LE }\end{array}$ & 0.56 & 0.50 & 0.33 & 0.35 & 0.10 & 0.30 & 0.27 & 0.20 & 0.39 & 0.05 & 0.13 & 0.25 & 0.36 & 0.17 \\
\hline Age group & \multicolumn{14}{|c|}{ Decomposition: contribution of age groups to changes in life expectancy (in \%) } \\
\hline 0 & 46.9 & 42.8 & 24.4 & 41.3 & 30.9 & 26.0 & 15.2 & 8.1 & 38.2 & 194.0 & 25.3 & 15.2 & 5.9 & 4.1 \\
\hline 1-14 & 25.4 & 15.3 & 18.2 & 10.4 & 5.4 & 6.2 & 4.8 & 3.2 & 9.4 & 37.1 & 7.8 & 1.8 & 2.7 & 2.2 \\
\hline $15-29$ & 5.6 & 15.2 & 13.7 & 9.2 & -1.7 & 4.0 & 5.3 & 2.9 & 7.7 & 18.6 & 5.4 & 4.7 & 2.0 & 4.3 \\
\hline $30-44$ & 7.3 & 10.9 & 12.9 & 7.9 & 8.7 & 5.8 & 5.1 & 6.7 & 7.6 & 37.4 & 7.6 & 3.0 & 5.1 & 8.0 \\
\hline $45-59$ & 5.8 & 6.7 & 13.4 & 8.8 & 3.3 & 12.9 & 13.6 & 8.0 & 5.4 & 30.5 & 13.6 & 8.8 & 14.5 & 11.7 \\
\hline $60-74$ & 6.9 & 7.3 & 13.2 & 15.1 & 39.6 & 22.2 & 25.3 & 32.0 & 13.1 & -43.6 & 23.0 & 27.2 & 36.4 & 29.1 \\
\hline $75+$ & 2.1 & 1.8 & 4.1 & 7.3 & 13.8 & 22.9 & 30.6 & 39.0 & 18.5 & -173.9 & 17.2 & 39.4 & 33.5 & 40.6 \\
\hline
\end{tabular}

Source: Statistisches Bundesamt 2012a, 2012b; own calculations

Notes:

Data from 1910-11 to 1932-34 refer to the German Empire; data from the Federal Republic of Germany (FRG) refer to West Germany including West Berlin from 1949-51 to 1988-90 and to western Germany excluding West Berlin for 2000-02; data for the German Democratic Republic (GDR) refer to East Germany including East Berlin from 1952-53 to 1988-89 and to eastern Germany excluding East Berlin for 2000-02; data for Germany from 2000-02 to 2009-11 refer to Germany as a whole. For 
trends between 1932-34 and 1949-51 we decided to contrast data for the German Empire with data for West Germany, as the latter represented around 1950 approximately three quarter of the population that lived in the German Empire at the end of World War II.

- Percentage values above 100 of the decomposition are related to strong improvements in mortality in that particular age group and usually small changes in overall life expectancy. For example, life expectancy at birth for women in the GDR increased only by 0.39 years between 1963-64 and 197172. Strong declines in infant mortality contributed to an increase in life expectancy at birth of 0.76 years; this increase was, however, counteracted by mortality increases at higher age groups, as indicated by the negative values.

- $\quad$ Colour thresholds decomposition: <0; 0-10; 10-20; 20+\% 


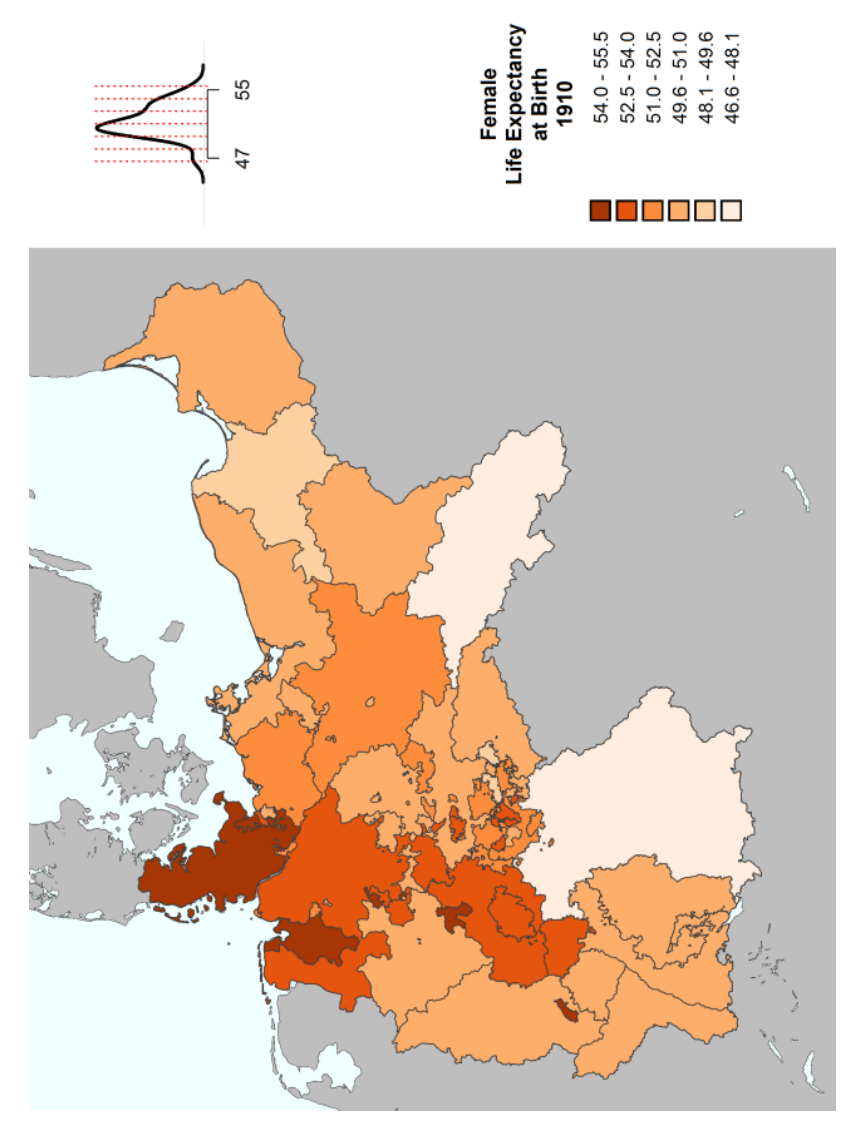

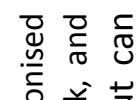

总

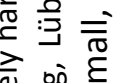

월 oํ है

응 용

응 돋ㅇ

낭

造

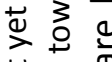

을

중

능 또

즁

焉 $\frac{0}{\pi}$

ᄃㅇำ

离

害吉

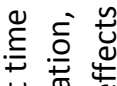

茂 $\frac{0}{5}$

홍응

吾产

흥
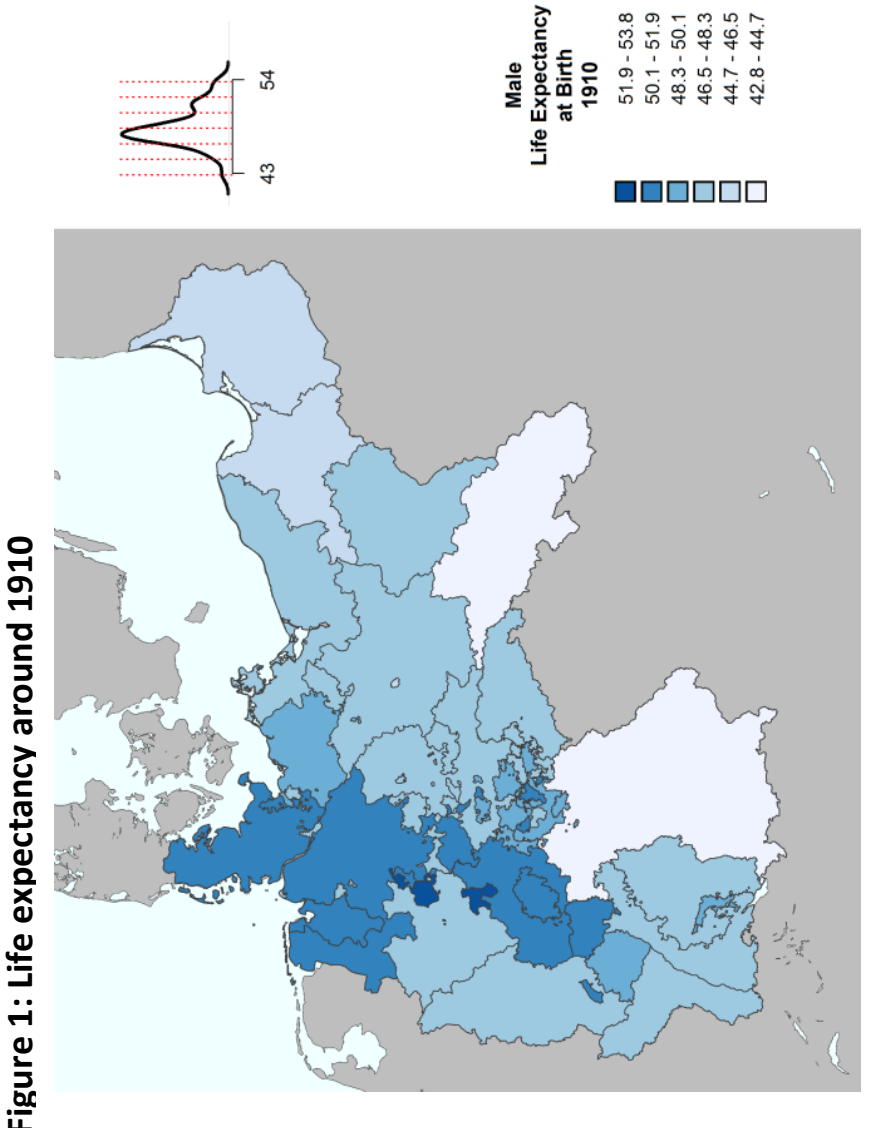

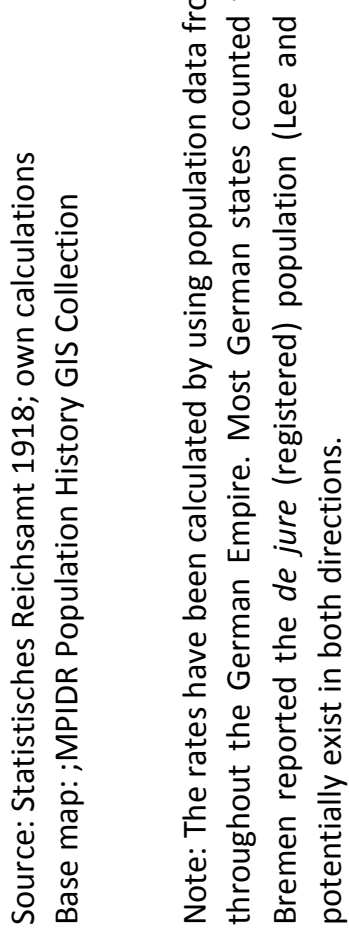




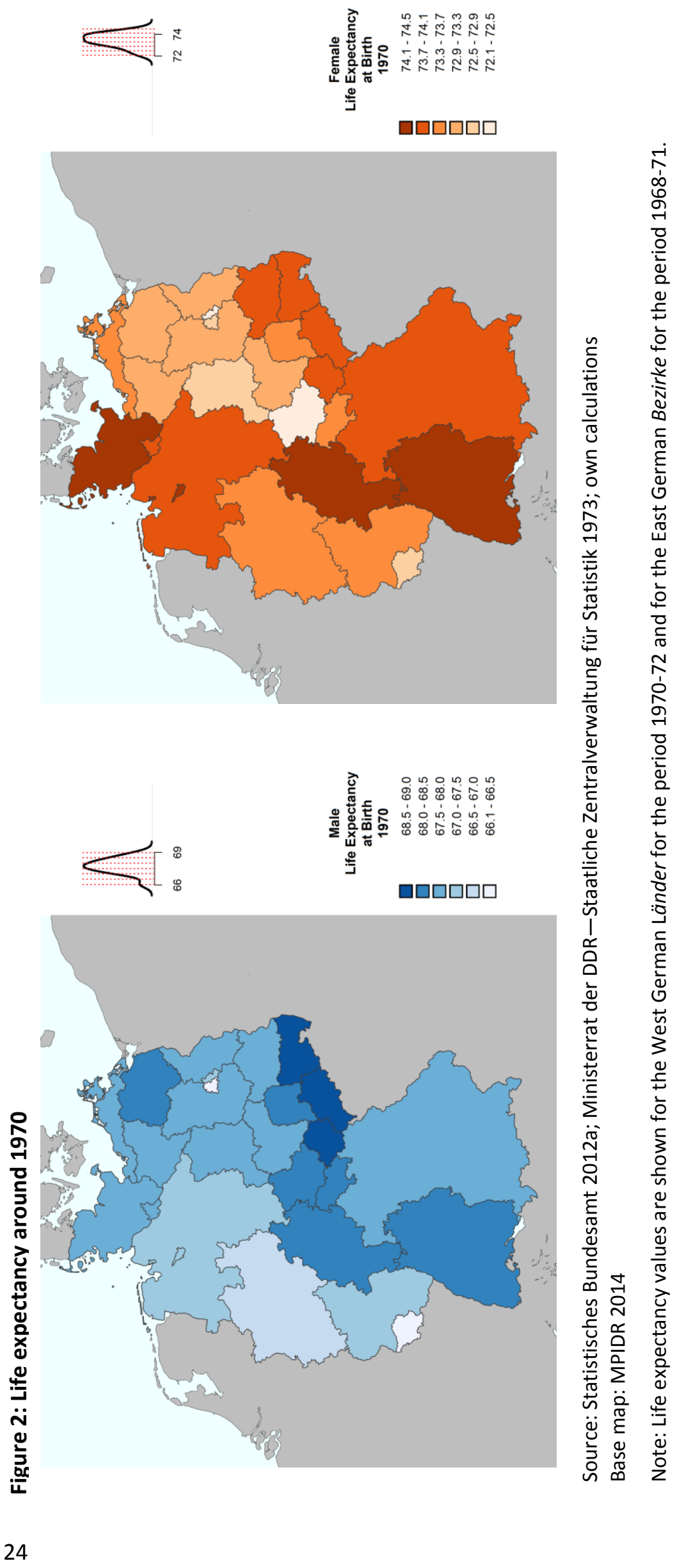


Figure 3: Life expectancy in 1995-97, 2002-04, 2009-11

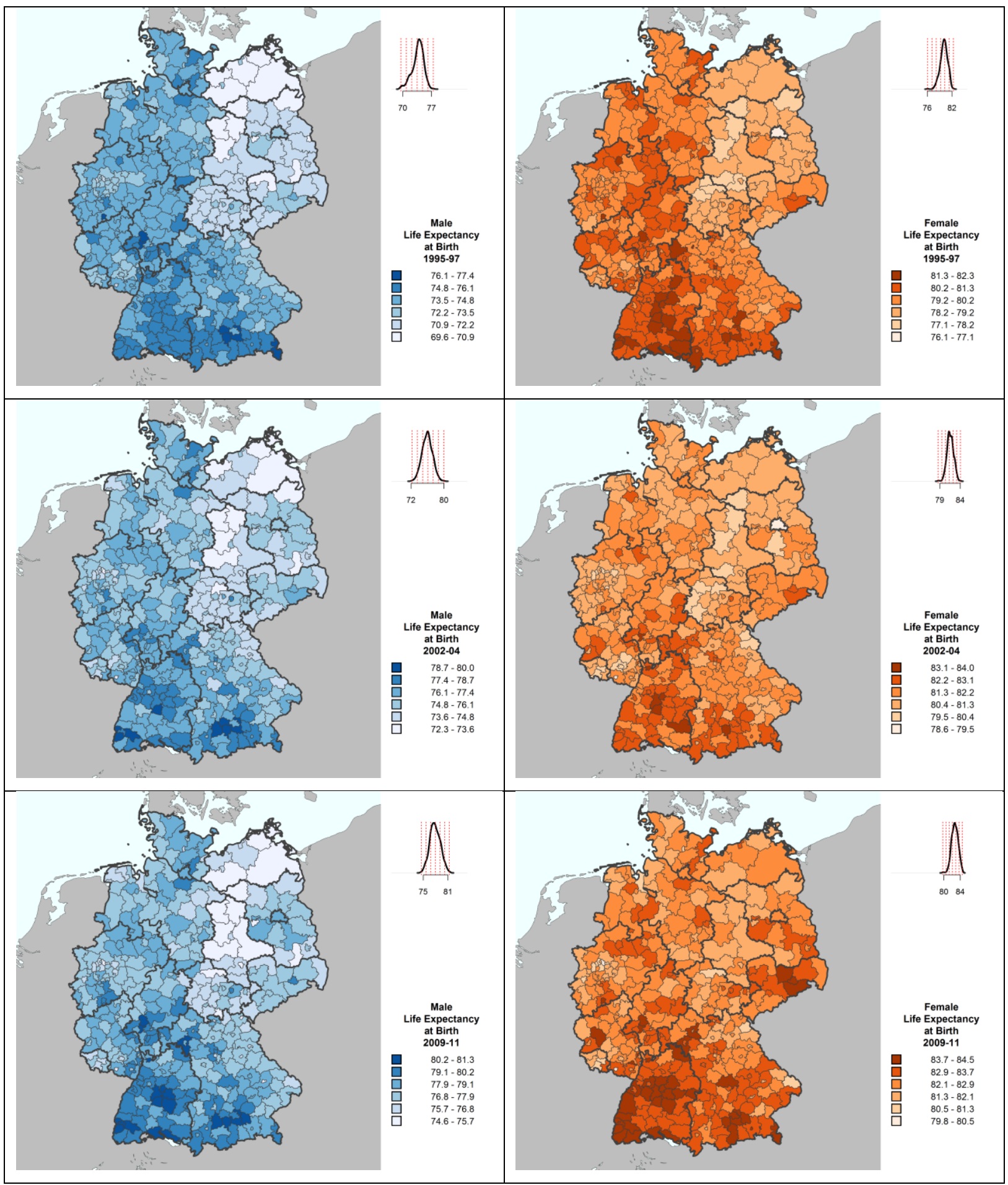

Source: Statistical offices of the Länder; Statistische Ämter des Bundes und der Länder 2014; own calculations

Base map: MPIDR 2014 
Appendix 1: Uncorrected GDP per capita vs. life expectancy at birth, 1910

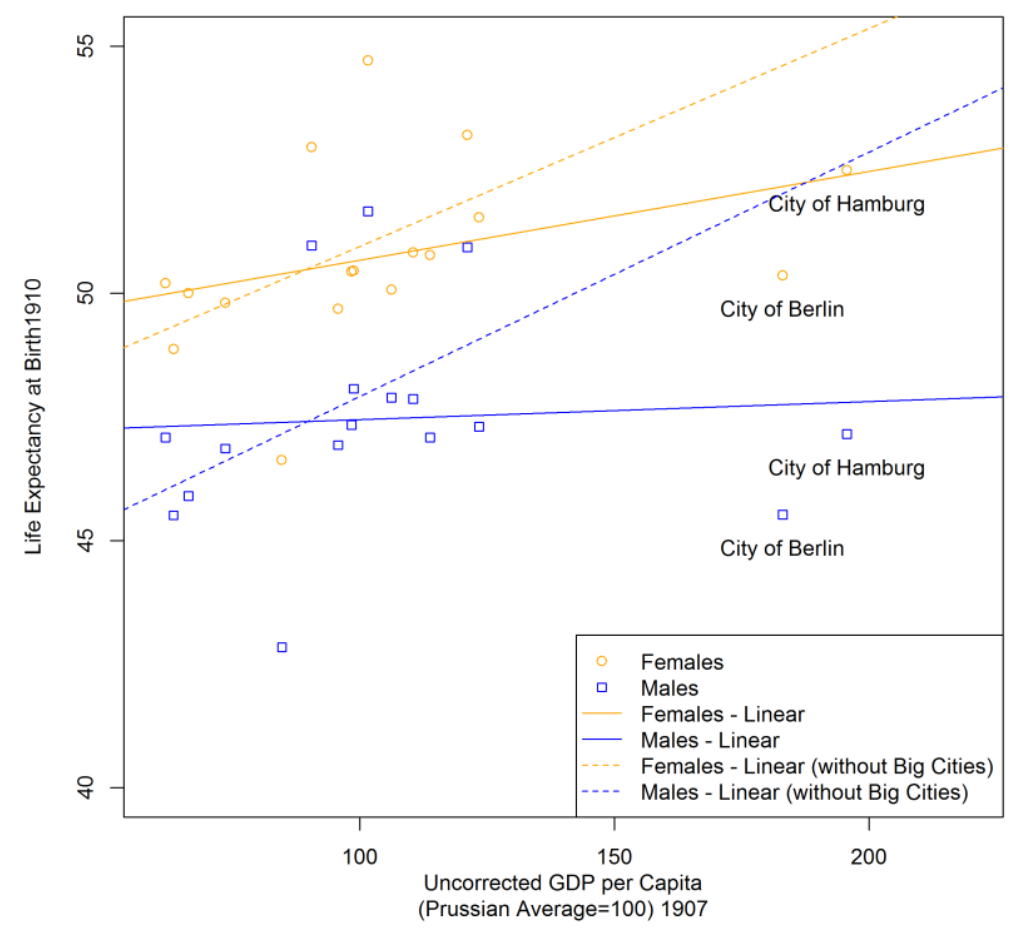

Source: Statistisches Reichsamt 1918; Hoffmann and Müller 1959 [2005]; own calculations

Note: The German regions covered in this analysis include the Prussian provinces and the German states Baden, Hamburg, Saxony, and Württemberg $(\mathrm{N}=18)$. These territories represented $77 \%$ of the population of the German Empire in 1910. The solid lines show the linear association between GDP and life expectancy for all regions; for the dashed line, the two cities Berlin and Hamburg have been excluded. 